\section{Germination of Papaya Seed in Response to Desiccation, Exposure to Subzero Temperatures, and Gibberellic Acid}

\author{
Antonieta N. Salomão ${ }^{1}$ and Rosângela C. Mundim² \\ Embrapa-Recursos Genéticos e Biotecnologia P.O. Box 02372-70849-970 \\ Brasília-DF Brazil
}

Additional index words. Carica papaya, dormancy, storage, gibberellin, liquid nitrogen

\begin{abstract}
The effects on germination of two lots of Carica papaya seed of dehydration at $25{ }^{\circ} \mathrm{C}$, followed by exposure to $-20{ }^{\circ} \mathrm{C}$ or $-196{ }^{\circ} \mathrm{C}$, were evaluated with and without gibberellic acid $\left(\mathbf{G A}_{3}\right)$ treatment. In the absence of $\mathbf{G A}_{3}$ treatment, dehydration increased subsequent germination only in seed lot 1 when moisture content (m.c.) was reduced from $59 \%$ to $6.0 \%$ and $5.3 \%$. In seed lot 2 , dehydration followed by exposure to $-196{ }^{\circ} \mathrm{C}$ increased germination compared with dehydration alone. Treatment with $\mathrm{GA}_{3}$ enhanced germination rate in all treatments. Dehydration to $5.3 \%$ (lot 1 ) or $6.9 \%$ and $6.8 \%$ m.c. (lot 2), followed by exposure to subzero temperatures and treatment with $\mathbf{G A}_{3}$, were the most favorable combined treatments to enhance papaya seed germination. The results suggest that papaya seed presents an orthodox behavior, permitting germplasm conservation in conventional and cryogenic genebanks.
\end{abstract}

The slow and asynchronous germination of papaya seeds is attributed to the presence of inhibitors (mainly phenolic compounds) in the sarcotesta and seed coat (Chow and Lin, 1991; Reyes et al., 1980). In addition, some seeds lack embryos (Nagao and Furutani, 1986).

Seed treatments to promote germination and to reduce germination time have been widely investigated. Satisfactory results were obtained by removing the sarcotesta (Gherardi and Valio, 1976; Lange, 1961; Pérez et al., 1980 ), sowing seeds at warm temperatures $\left(30^{\circ} \mathrm{C}\right.$ or 20 to $30^{\circ} \mathrm{C}$ ) (Yahiro, 1979), exposing dry seeds to $10^{\circ} \mathrm{C}$ prior to sowing (Hore and Sen, 1993), drying seeds (Sippel and Claassens, 1993), and soaking seeds in distilled water, potassium nitrate, thiourea, sodium thiosulfate, tannic acid or ferulic acid (Furutani and Nagao, 1987; Hore and Sen, 1993; Nagao and Furutani, 1986; Olalde and Hernandez, 1988; Pérez et al., 1980).

There are conflicting reports in the literature about the effect of gibberellins on papaya seed germination; some have observed stimulation (Andreoli and Khan, 1993; Furutani and Nagao, 1987; Lange, 1961;

Received for publication: 16 Feb. 1999. Accepted for publication: 22 Nov. 1999. We are indebted to the referees for constructive criticism during the review process, and to A.C. Allem, J.R. Moreira, and M. Eira who reviewed an earlier draft. The cost of publishing this paper was defrayed in part by the payment of page charges. Under postal regulations, this paper therefore must be hereby marked advertisement solely to indicate this fact.

${ }^{1}$ Researcher. E-mail address: antoniet@cenargen. embrapa.br

${ }^{2}$ Research Assistant.
Nagao and Furutani, 1986; Yahiro and Oryoji, 1980), others no effect (Begum et al., 1988; Chacko and Singh, 1966; Ramirez, 1961).

The effects of storage on germinability are also variable. Germination remained almost unaltered when seeds were stored at 5, 10 and $15^{\circ} \mathrm{C}$ (Bass, 1975; Ellis et al., 1991; Pérez et al., 1980). However, germination declined if they were stored in dry or imbibed conditions at room temperatures or at $-20{ }^{\circ} \mathrm{C}$ (Begum et al., 1988; Ellis et al., 1991; Vázquez-Yanes and Orozco-Segovia, 1996).

Given such conflicting results, germplasm of papaya is traditionally conserved in field genebanks and therefore exposed to environmental hazards. The storage of papaya seeds in conventional genebanks could prevent losses of important genetic material and would be less costly.

The objective of this research was to evaluate the effects of dehydration and of exposure to $-20{ }^{\circ} \mathrm{C}$ and $-196{ }^{\circ} \mathrm{C}$, and their interactions with gibberellic acid, on papaya seed germination.

\section{Materials and Methods}

Seed source. Mature fruits of two different lots of papaya were used in the experiment. Seeds were extracted from the fruits and mixed thoroughly. The sarcotesta was removed by rubbing the seeds in a sieve under tap water followed by washing in distilled water.

Dehydration and storage at subzero temperatures. Seeds from both lots were kept in hermetically sealed plastic boxes containing silica gel (5 g silica : $1 \mathrm{~g}$ seed) at room temperature (ca. $25^{\circ} \mathrm{C}$ ) for 0 (control), 1,2 , or $3 \mathrm{~d}$. Seeds were placed in plastic cryotubes and exposed for $3 \mathrm{~d}$ to $-20^{\circ} \mathrm{C}$ (seed lot 1 ) or -196 ${ }^{\circ} \mathrm{C}$ (seed lot 2) (by direct immersion in liquid nitrogen) after each dehydration period. Seeds were subsequently thawed at room temperature for $3 \mathrm{~h}$.

Germination tests. Germination tests were carried out following each dehydration period and dehydration-storage temperature combination with four replicates of 25 seeds each. Seeds were placed in petri dishes on cotton saturated with distilled water or GA solution $\left(\mathrm{GA}_{3} 10^{-3} \mathrm{M}\right)$, and germinated at $30{ }^{\circ} \mathrm{C}$ under a $12 \mathrm{~h}$ photoperiod. Radicle protrusion (length $\geq 1.0 \mathrm{~cm}$ ) after at least 1 week was the criterion for successful seed germination. The results were expressed as final germination percentage. The average germination time [T (day)] was calculated according to Labouriau and Pacheco (1979): $\mathrm{T}($ day $)=\Sigma \mathrm{ni} \cdot \mathrm{ti} / \Sigma \mathrm{ni}$, where $\mathrm{ni}=$ number of seeds germinated between observations at times ti- 1 and ti; and $\mathrm{ti}=$ time in $\mathrm{d}$.

Statistical analysis. Germination percentages were subjected to two-way analysis of variance (ANOVA) followed by Bonferroni post-tests, for each temperature.

Determination of seed moisture content. The moisture content (m.c.) after each dehydration period was determined by oven-drying three replicates of 10 seeds each at $105^{\circ} \mathrm{C}$ for $2 \mathrm{~d}$. The results were expressed as an average percentage on a fresh weight basis.

\section{Results}

Initial seed m.c. values were $59 \%$ (lot 1) and $67 \%$ (lot 2) (Table 1). Drying was rapid and equilibrium was reached after $2 \mathrm{~d}$ over silica gel at room temperature. Seeds from both lots germinated poorly if not dried or treated with $\mathrm{GA}_{3}$ (Table 1). Drying alone markedly improved germination of lot 1 , but had no effect on that of lot 2 . Treatment with $\mathrm{GA}_{3}$ did not improve germination of dried seeds of lot 1 , but was effective in lot 2 . The interaction between $\mathrm{GA}_{3}$ and seed moisture content was significant for both seed lots.

Lot 1 seeds, dehydrated and exposed to $-20^{\circ} \mathrm{C}$ for $3 \mathrm{~d}$, germinated in either water or $\mathrm{GA}_{3}$ (Table 2). The germination rate was enhanced by $\mathrm{GA}_{3}$, irrespective of moisture content. In the presence of water, the highest germination percentages occurred with seeds submitted to 2 and $3 \mathrm{~d}$ of dehydration. The interaction between $\mathrm{GA}_{3}$ and seed moisture content was nonsignificant after seed exposure to $-20{ }^{\circ} \mathrm{C}$ (Table 2 ).

The effect of $\mathrm{GA}_{3}$ on dehydrated seeds was similar to that of exposure to $-196{ }^{\circ} \mathrm{C}$ for $3 \mathrm{~d}$ (compare Tables 1 and 2). In seeds exposed to $-196{ }^{\circ} \mathrm{C}$, germination rate was enhanced by $\mathrm{GA}_{3}$, but the final germination percentages were similar for water and $\mathrm{GA}_{3}$ (Table 2). The interaction between $\mathrm{GA}_{3}$ and seed moisture content was nonsignificant after seed exposure to $-196{ }^{\circ} \mathrm{C}$. 
Table 1. The effects of dehydration of papaya seeds at $25^{\circ} \mathrm{C}$ and subsequent treatment with $\mathrm{GA}_{3}$ on germination $(\mathrm{G})$ and average germination time $(\mathrm{T})$.

\begin{tabular}{|c|c|c|c|c|c|c|c|c|}
\hline \multirow{2}{*}{$\begin{array}{l}\text { Dehydration } \\
\text { period (d) }\end{array}$} & \multicolumn{4}{|c|}{ Seed lot 1} & \multicolumn{4}{|c|}{ Seed lot 2} \\
\hline & m.c. $(\%)$ & $\mathrm{GA}_{3}$ & $\mathrm{G}(\%)$ & $\mathrm{T}(\mathrm{d})( \pm \mathrm{SE})$ & m.c. $(\%)$ & $\mathrm{GA}_{3}$ & $\mathrm{G}(\%)$ & $\mathrm{T}(\mathrm{d})( \pm \mathrm{sE})$ \\
\hline \multirow[t]{2}{*}{0} & 59.0 & --- & 6 & $25(\mathrm{ND})^{\mathrm{z}}$ & 67.0 & --- & 1 & $8(\mathrm{ND})^{\mathrm{z}}$ \\
\hline & & + & 86 & $8(2.6)$ & & + & 71 & $9(2.5)$ \\
\hline \multirow[t]{2}{*}{1} & 6.0 & --- & 85 & $24(3.3)$ & 8.4 & --- & 0 & \\
\hline & & + & 80 & $15(5.4)$ & & + & 74 & $8(3.1)$ \\
\hline \multirow[t]{2}{*}{2} & 5.3 & --- & 85 & $21(4.3)$ & 6.9 & --- & 0 & \\
\hline & & + & 90 & $12(1.6)$ & & + & 77 & $8(3.5)$ \\
\hline \multirow[t]{3}{*}{3} & 5.3 & --- & 75 & $21(2.8)$ & 6.8 & --- & 0 & \\
\hline & & + & 65 & $11(0.8)$ & & + & 75 & $9(3.7)$ \\
\hline & & & & Significance & & & & \\
\hline $\mathrm{GA}_{3}$ & & & $* *$ & & & & $* * *$ & \\
\hline m.c. & & & $* * *$ & & & & NS & \\
\hline $\mathrm{GA}_{3} \times$ m.c. & & & **** & & & & **** & \\
\hline
\end{tabular}

${ }^{\mathrm{z} S t a n d a r d ~ e r r o r ~ n o t ~ d e t e r m i n e d ~ s i n c e ~ g e r m i n a t i o n ~ o n l y ~ r e c o r d e d ~ i n ~ o n e ~ r e p . ~}$

Ns, ${ }^{* *}, * * * *$ Nonsignificant or significant at $P \leq 0.001$ or 0.0001 .

Table 2. The effects on papaya seeds germination $(\mathrm{G})$ and average germination time $(\mathrm{T})$ of dehydration at $25^{\circ} \mathrm{C}$ and exposure for $3 \mathrm{~d}$ to $-20^{\circ} \mathrm{C}$ (lot 1$)$ or $-196^{\circ} \mathrm{C}$ (lot 2)

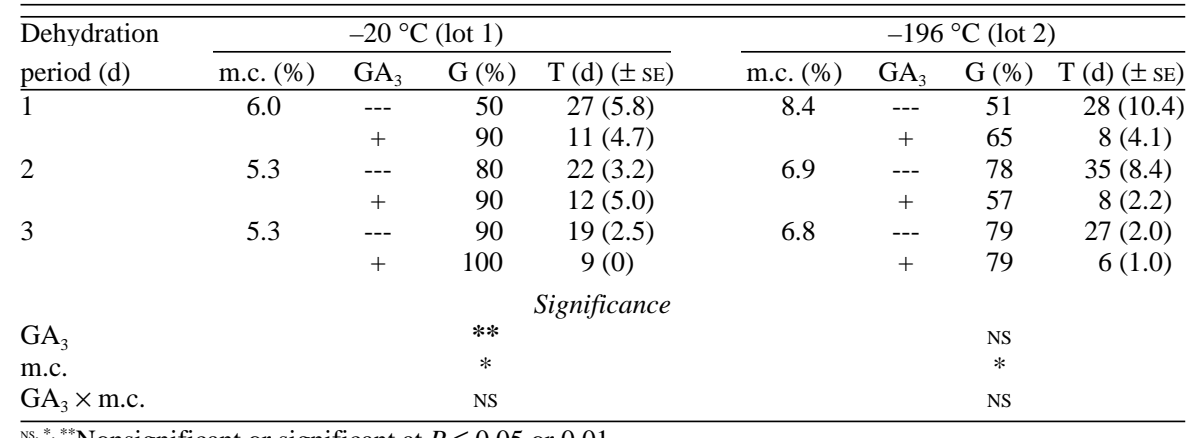

${ }_{\mathrm{ss},}^{*, * *}$ Nonsignificant or significant at $P \leq 0.05$ or 0.01 .

\section{Discussion}

According to the literature, the removal of sarcotesta, with or without desiccation, reduces the level of dormancy in papaya seeds. The combined treatments (removal of sarcotesta and seed desiccation) promoted germination of seed lot 1 , but did not of lot 2 , in water. Thus the seed lots responded differently to desiccation. The effectiveness of $\mathrm{GA}_{3}$ in breaking dormancy and accelerating germination indicates that a chemical inhibitor may have been present (Chow and Lin, 1991; Reye et al., 1980) and that $\mathrm{GA}_{3}$ was effective, regardless of seed moisture content. Seeds of both lots tolerated desiccation without injury.

Exposure to $-20{ }^{\circ} \mathrm{C}$ did not reduce seed germinability, and the seeds maintained their ability to germinate with or without $\mathrm{GA}_{3}$. Germination after $-20^{\circ} \mathrm{C}$ treatment appeared to be influenced by seed m.c. Seeds dehydrated for $3 \mathrm{~d}$ (5.3\% m.c.) germinated better irrespective of the germination medium (water or $\mathrm{GA}_{3}$ ). The positive effect of exposure to $-20{ }^{\circ} \mathrm{C}$ strengthens the conclusion that papaya seed shows an orthodox behavior. However, this result is in disagreement with the related observation that papaya germinability was affected negatively by storage at $-20{ }^{\circ} \mathrm{C}$ (Ellis et al., 1991). These contrasting findings may explain the varia- tion in the degree of dormancy and the requirements for breaking it exhibited by different seed populations of papaya (Baskin and Baskin, 1998).

Exposure to liquid nitrogen $\left(-196{ }^{\circ} \mathrm{C}\right)$ enhanced seed germination without $\mathrm{GA}_{3}$ treatment, and $\mathrm{GA}_{3}$ treatment did not affect response; however, seeds took longer to germinate. One possible explanation for this is that ultra-low temperature may induce cracks in the seed coat (Busse, 1930; Jordan et al., 1982), thus promoting imbibition and the release of inhibitors present within the seed. In addition, the rapid cooling and the slow thawing probably prevented any detrimental effects of exposure to liquid nitrogen. Previous results have shown that papaya seed with $10 \%$ (Becwar et al., 1983) or 9\% m.c. (Chin and Krishnapillay, 1989) survived exposure to liquid nitrogen.

The results reported here suggest that gibberellic acid, irrespective of seed m.c. and exposure to subzero temperatures, had a positive effect on germination and also reduced average germination time. Depending on the seed lot, dehydration improved but did not accelerate germination in water or had no effect on seed germination. Exposure to subzero temperatures promoted seed germination. In addition, dehydration improved germination in both water and $\mathrm{GA}_{3}$. The best combined treatments to enhance germination were dehydration to $5.3 \%$ m.c. and exposure to $-20{ }^{\circ} \mathrm{C}$ (lot 1$)$, and dehydration to $6.9 \%$ or $6.8 \%$ followed by exposure to $-196{ }^{\circ} \mathrm{C}$ (lot 2 ). Papaya seeds showed an orthodox response to desiccation and exposure to subzero temperatures. This suggests that they may be conserved in both conventional and cryogenic genebanks.

\section{Literature Cited}

Andreoli, C. and A.A. Khan. 1993. Improving papaya seedling emergence by matriconditioning and gibberellin treatment. HortScience 28:708709.

Baskin, C.C. and J.M. Baskin. 1998. Causes of within species variations in seed dormancy and germination characteristics, p. 181-207. In: C.C. Baskin and J.M. Baskin (eds.). Seeds ecology, biogeography, and evolution of dormancy and germination. Academic, San Diego.

Bass, L.N. 1975. Seed storage of papaya. HortScience 10:232.

Becwar, M.R.,P.C. Stanwood, and K.W.Leonhardt. 1983. Dehydration effects on freezing characteristics and survival in liquid nitrogen of desiccation-tolerant and desiccation-sensitive seeds. J. Amer. Soc. Hort. Sci. 108:613-618.

Begum, H., M.L. Lavania, and G.H.V. Ratna Babu. 1988. Seed studies in papaya. II. Effects of presoaking treatments with gibberellic acid and thiourea on germination and vigour of aged seed. Seed Res. 16(1):51-56.

Busse, W.F. 1930. Effect of low temperatures on germination of impermeable seeds. Bot. Gaz. 89:169-179.

Chacko, E.K. and R.N. Singh. 1966. The effect of gibberellic acid on the germination of papaya seeds and subsequent seedling growth. Trop. Agr. 43:341-346.

Chin, H.F. and B. Krishnapillay. 1989. Cryogenic storage of some horticultural species. Acta Hort. 253:107-112.

Chow, Y.J. and C.H. Lin. 1991. p-Hydroxy benzoic acid as the major phenolic germination inhibitor of papaya seed. Seed Sci. Technol. 19:167-174.

Ellis, R.H., T.D. Hong, and E.H. Roberts. 1991. Effect of storage temperature and moisture on the germination of papaya seeds. Seed Sci. Res. 1:69-72.

Furutani, S.C. and M.A. Nagao. 1987. Influence of temperature, $\mathrm{KNO}_{3}, \mathrm{GA}_{3}$ and seed drying on emergence of papaya seedlings. Scientia Hort. 32:67-72.

Gherardi, E. and I.F.M. Valio. 1976. Occurrence of promoting and inhibitory substances in the seed arils of Carica papaya L. J. Hort. Sci. 15:1-14.

Hore, J.K. and S.K. Sen. 1993. Viability of papaya (Carica papaya L.) seeds under different prestorage treatments. Environ. and Ecol. 11(2):273-275.

Jordan, J.L., L.S. Jordan, and C.M. Jordan. 1982. Effects of freezing to $-196^{\circ} \mathrm{C}$ and thawing on Setaria lutescens seeds. Cryobiology 19:435442

Labouriau, L.G. and A. A. Pacheco. 1979. Isothermal germination rates in seeds of Dolichos biflorus L. Bol. Soc. Venezuelana de Ciencias Naturales 136(34):73-112.

Lange, A.H. 1961. Effect of the sarcotesta on germination of Carica papaya. Bot. Gaz. 122:305-311.

Nagao, M.A. and S.C. Furutani. 1986. Improving germination of papaya seed by density separation, potassium nitrate and gibberellic acid. HortScience 21:1439-1440. 


\section{Seed Technology}

Olalde, E.M. and M.R. Hernandez. 1988. Influencia de diferentes bioestimulantes y reguladores del crecimiento en la germinación de la semilla de papaya (Carica papaya L.) y su posterior crecimiento. Rev. Centro Agr. 15(2):41-49.

Pérez, A., M.N. Reyes, and J. Cuevas. 1980. Germination of two papaya varieties: Effect of seed aeration, K-treatment, removing of the sarcotesta, high temperature, soaking in distilled water and age of seeds. J. Agr. Univ. Puerto Rico 64:173180.
Ramirez, O.D. 1961. Effect of gibberellic acid on germination of papaya (Carica papaya $\mathrm{L}$.) seeds. J. Agr. Univ. Puerto Rico 45:188-190.

Reyes, M.N., A. Pérez, and J. Cuevas. 1980. Detecting endogenous growth regulators on the sarcotesta, endosperm and embryo by paper chromatography on fresh and old seeds of two papaya varieties. J. Agr. Univ. Puerto Rico 64:164-172.

Sippel, A.D. and N.J.F. Claassens. 1993. The effect of differentseed treatments on germination of Carica papaya L. Inligtingsbulletin-Instituut vir Tropiese en Subtropiese Gewasse 250:16-19.

Vázquez-Yanes, C. and A. Orozco-Segovia. 1996. Comparative longevity of seeds of five tropical rain forest woody species stored under different moisture conditions. Can. J. Bot. 74:16351639.

Yahiro, M. 1979. Effects of seed pre-treatments on the promotion of germination in papaya, Carica papaya L. Mem. Fac. Agr. Kagoshima 15:49_ 54. 